\title{
Description of the cumulative incidence of COVID- 19 in the 10 cities of Mexico with most accumulated cases after 120 days of the first confirmed case
}

\begin{abstract}
Background: The COVID-19 is potentially severe acute respiratory infectious disease, increasing day by day. The cumulative incidence of coronavirus disease (COVID-19) cases is showing similar trends in the globally confirming that, while at a different stage depending on the country, the COVID-19 pandemic has progressed rapidly in all countries. In this study, we evaluate the cumulative incidence of COVID-19 in 10 cities located in all regions of Mexico
\end{abstract}

Material and methods: Confirmed COVID-19 cases were obtained from the Government of Mexico's open data portal. A listing of the metropolitan zones with most cases was built.

Results: At the time of the data cut-off point, COVID-19 confirmed cases in the Valle de Mexico metropolitan area are more than 233000 , with a cumulative incidence of 183 cases/100 000 habitants. Even though Valle de Mexico has the highest reported number of cases, it is Villahermosa city which has the highest cumulative incidence with 647 cases/100 000 habitants.

Conclusions: The estimation of cases through the Sentinel model has shown that, the real extension of the epidemic could be at least 8 times higher that official data; a situation that would place Mexico as one of the most affected countries in Latin America.
Volume 9 Issue 4 - 202I

\section{Eduardo Moreno-Vázquez, Elsa Tamayo- Legorreta}

Centro de Investigación sobre Enfermedades Infecciosas, Instituto Nacional de Salud Pública, México

Correspondence: Elsa María Tamayo-Legorreta, Centro de Investigación sobre Enfermedades Infecciosas, Instituto Nacional de Salud Pública. Av. Universidad 655, col. Santa María Ahuacatitlán. 62100 Cuernavaca, Morelos, México, Tel 527773293000 ext. 2233,Email emtamayo@insp.mx

Received: July 06, 202I | Published: July 15, 2021

Keywords: SARS-CoV-2, Covid-19, cumulative incidence, Mexico

\section{Introduction}

On December $31^{\text {st }}, 2019$, a pneumonia outbreak of unknown etiology emerged in Wuhan City, Hubei province, in China. A new virus of the $\beta$-coronavirus family (SARS-CoV-2) was identified as causal agent of the coronavirus disease, COVID-19., ${ }^{1,2}$ The rapid spread of the disease lead to the World Health Organization (WHO) to catalogue the COVID-19 as a sanitary emergency on January $30^{\text {th }}$, 2020 , based on the impact that the virus will have in developing countries with less sanitary infrastructure; and on March $11^{\text {th }}, 2020$, the WHO declared the situation as a pandemic, after evaluating the spread and severity of the COVID-19..$^{3-5}$ Mexico reported its first COVID-19 case on February $28^{\text {th }}, 2020$, followed by a clear rise on the number of cases. ${ }^{6,7}$ The COVID-19 pandemic is a big thread to the global health, with 10874695 cases and 521451 confirmed deaths in 218 countries as of June 25 $5^{\text {th }}, 2020$ : with the United States, Brazil, United Kingdom, Italy, and France being the countries with the higher number of deaths. Mexico and Spain also reported more than 28000 deaths. ${ }^{8-14}$ In this study, we evaluated the number of cases and the increase in the cumulative incidence of COVID-19 in 10 cities located in all regions of Mexico: Villahermosa, Mexicali, Veracruz, Acapulco, Valle de Mexico, Puebla, Toluca, León, Monterrey, and Guadalajara; and they were compared with data from New York City, Brazil, Ecuador, Peru, and Chile within the period of February 25 2020, and June $25^{\text {th }}, 2020$.

\section{Methods}

Official data of confirmed COVID-19 cases and population of each county were obtained from the open data portal of Mexico's government. ${ }^{13}$ In the data base, confirmed cases are classified according to the onset of symptoms date. This strategy causes that, for obtaining the confirmed cases of a specific date, it can take up to fourteen days, timeframe between the symptoms onset of each person, searching of attention on the health services, sample processing and report of results. The data base was downloaded on July $9^{\text {th }}, 2020$ and includes the number of people with a positive COVID-19 test that started symptoms in each day, in each county, which we will call "New Cases". With this information, we calculated the cumulative positive cases per day.

A listing of the metropolitan areas of Mexico with the highest number of cases was built. For defining each metropolitan area, we considered the counties classified as physical conurbation, according to the INEGI classification. ${ }^{14}$ The population and the confirmed COVID-19 cases of each county were summed for each metropolitan area.

\section{Results}

The first case of COVID-19 in Mexico was reported on February 27h, 2020, in Mexico City. Since then, and up to June $25^{\text {th }}, 2020$, (120 
days), 233845 cases have been reported along the country. The 10 cities with the most reported cases of COVID-19 represent $31.9 \%$ of the population of the country, and $51.5 \%$ of the total cases (Table 1 ).
With exception of Valle de Mexico, the rest of the cities reported their first case between the second and the third week of March 2020.

Table I Cumulative incidence of the 10 cities with the most cases of Coronavirus as of June 25, 2020

\begin{tabular}{|c|c|c|c|c|}
\hline Cities & Population & Day I & Cumulative cases & Cumulative incidence \\
\hline México & 127792286 & $27-F e b-20$ & 233845 & 183 \\
\hline Valle de México² & 20921500 & 27-Feb-20 & 74899 & 358 \\
\hline Monterrey ${ }^{2}$ & 4754893 & I0-Mar-20 & 5505 & 116 \\
\hline Guadalajara $^{2}$ & 5139874 & II-Mar-20 & 4831 & 94 \\
\hline Puebla $^{2}$ & 2696493 & II-Mar-20 & 8852 & 328 \\
\hline Mexicali² $^{2}$ & I 087478 & II-Mar-20 & 5261 & 484 \\
\hline León ${ }^{2}$ & 1679610 & 13-Mar-20 & 3806 & 227 \\
\hline Toluca $^{2}$ & I 990826 & 13-Mar-20 & 4820 & 242 \\
\hline Acapulco $^{2}$ & 840795 & 13-Mar-20 & 3139 & 373 \\
\hline Veracruz $^{2}$ & 779728 & I5-Mar-20 & 3564 & 457 \\
\hline Villahermosa ${ }^{2}$ & 888867 & 18-Mar-20 & 5753 & 647 \\
\hline Total & 40780064 & 18-Mar-20 & 120430 & 295 \\
\hline
\end{tabular}

'Per 100,000 population

${ }^{2}$ Selected cities with the most COVID-19 cases as of June 25, 2020

Of all cities analyzed, Valle de Mexico is the most populated (Mexico City and metropolitan area), representing 16.4\% of national population and concentrating $32 \%$ of total cases, showing a cumulative incidence of 358 cases/100 000 habitants. However, the city with the higher cumulative incidence is Villahermosa, with 647 cases/100 000 habitants, becoming the third most affected city with $2.5 \%$ of all cases and having only $0.7 \%$ of the national population
(Table 1). All cities reached a cumulative incidence of 1 case per 100 000 habitants within the first 14 days of their epidemic, taking as first day the day on which, they reported their first case; except for Valle de Mexico, which reached the same cumulative incidence at the day 20In contrast, for reaching a cumulative incidence of 10 cases/100 000 habitants, the period is longer and goes from 17 days in Villahermosa to 64 days for Guadalajara (Figure 1).

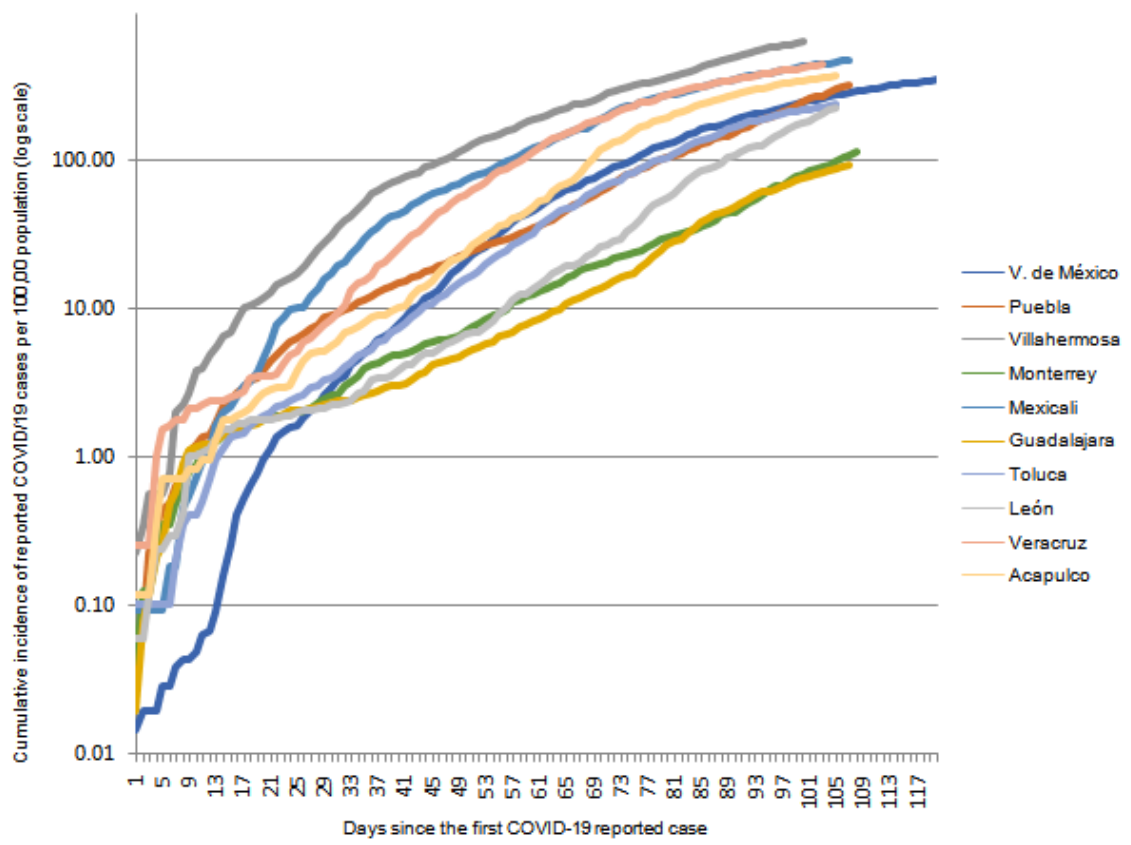

Figure I Time distribution of the cumulative incidence of reported Covid-19 since the first case. 


\section{Discussion}

The pandemic caused by SARS-CoV-2 has become one of the most important health challenges globally in this century. The trends observed in the cumulative incidence of COVID-19 suggest that the pandemic progressed at a similar rhythm in all countries, even when they were in different stages of the pandemic, had variations in the national public health response and maybe different case definitions, and had different protocols for selection of eligible patients for Covid testing, including tests for confirming recovering.

The analysis of the data is useful for reconstructing the first months of the COVID-19 pandemic in Mexico. The first case of COVID-19 was detected on February $27^{\text {th }}, 2020$, in Mexico City, the city with the most flux of international travelers in the country. This case was a person coming from Italy when the cases were rising in that region of the world. After this case, Valle de Mexico remained practically as the only city where COVID-19 cases were reported along two weeks (only four cases more were reported, each one in four different cities), until March $10^{\text {th }}, 2020$, when the epidemics began in the rest of the cities analyzed, almost synchronically, along eight days. The reason of this fact could be that, initially, the suspicious case definition was only able to detect imported cases (people with symptoms within the last 14 days, which had contact with a confirmed or suspected case of COVID-19, or travel history to affected regions). ${ }^{15}$

Official data of confirmed COVID-19 cases and population of each county derivated from the open data portal of Mexico's government.

Positive cases with stat date from March $10^{\text {th }}$ could be the first cases of local transmission detected in the country, but it cannot be assured due to the suspicious case definition current in that week; any other person with symptoms that have reached out to the health services it is very likely that was not tested for SARS-CoV-2. Except for Valle de Mexico, all cities reached a cumulative incidence of one case per 100000 habitants in a timeframe of 14 days since their first case, between March $17^{\text {th }}$ and $25^{\text {th }}, 2020$. Valle de Mexico lasted 20 days for reaching one case per 100 habitants, but this occurred in the same period as the other cities did.

The Jornada Nacional de la Sana Distancia (National Stage of Healthy Distance) started on March $23^{\text {rd }}, 2020$, and only Guadalajara, Monterrey and Leon showed an evident decrease in the COVID-19 incidence. Veracruz also showed an important decrease in the incidence in an early stage of its epidemic, around the day five (March 19th); however, the city experimented a sharply rise in the incidence of cases approximately two weeks after, which lead it to became among the three cities with the most cumulative incidence along the entire period of analysis. The rest of the cities seem to have a similar shape of their epidemic curves, with a decrease in the growth of the cumulative incidence in the first days of their epidemic, but without being as horizontals as observed for Guadalajara, Monterrey, and Leon during two or three weeks. ${ }^{8,10,11}$

The results of this work have, at least, three limitations. First, the reported cases of COVID-19 are very probable underestimated due to the focused detection only among the serious cases and the delays on the reporting. It is probable that reported deaths are also underestimated due to the incomplete following up of all reported COVID-19 cases, additionally to the deaths of infected people that ware not diagnosed or that died in their homes. Second, the level and criteria of notification can vary from one city to another, and this can contribute to the geographic variation observed in this analysis; for example, asymptomatic cases are not officially reported because, under some state health systems criteria, they are not considered positive cases. Finally, the estimations of cases, deaths, lethality rates and changes in the cumulative incidence at state level cannot be comparable between cities because the number of tests varies broadly, moreover the accelerated increases in the detection of COVID-19 cases have become a high load in the health system infrastructure, which leads to delays in the notifications of results that differ from state to state.

Following up on changes of reported cases and the incidence of diseases within communities along the time is fundamental for understanding and a answering to the evolution of local COVID-19 epidemics. The changing magnitude and incidence within a state contributes to the decision making for implementing mitigation strategies in the community, including social distancing and equal monetary and human resources assignation, like those used for medical attention infrastructure.

With data obtained from Sentinel epidemiological vigilance model, it has been calculated that COVID-19 epidemic is, at least, eight times higher that reported; this means that, for each confirmed positive case, there are another eight possible cases unregistered because, either they did not look for a doctor, or they were asymptomatic, or testing was not considered necessary. The disadvantage of this model is that was not designed for an epidemic like COVID-19 because many regions of Mexico are not covered. In the case of South America countries, the model called Epicovid19-BR indicates that, for each confirmed positive case there are another six that also were infected but were not tested. ${ }^{9}$ Information about cases at city level is scarce globally. One of the most detailed information sources is about New York City; after 120 days of their first case the cumulative incidence in this city was 2536 cases per 100000 habitants, which represent around four times higher than the cumulative incidence of Villahermosa, Tabasco, or eight times higher than cumulative incidence observed in Valle de Mexico. However, a big difference is that New York City experimented a major part of its epidemic curve in just three months, ${ }^{11,16}$ meanwhile, in the analyzed cities, after 120 days of the first reported case, the epidemic curves are still rising or seems to have reached their higher level, in the best of the cases.

The available information, in most of the cases, was collected to country level and it is difficult to compare with the one compiled in Mexico due to differences in the epidemiologic approach, highlighting the low number of diagnostic tests that Mexico performs as the main difference. For example, as of our data cut-off day (June $\left.25^{\text {th }}, 2020\right)$, Equator performed almost twice tests as Mexico, Brazil nine more times, Peru 10, Chile 11 and United States of America 23 more times. ${ }^{17}$ Brazil is the country with more reported cases in Latin America and the second in the world, after United States, and have reached one million of infected people in 114 days (from February $26^{\text {th }}$ to June $19^{\text {th }}, 2020$ ) since the first diagnosed case in the country, meanwhile in United States of America it took 98 days (From January $21^{\text {st }}$ to April 29 $\left.9^{\text {th }}, 2020\right)$. Moreover, Equator, with more than 50000 confirmed cases and 4400 deaths, is the fourth place in Latin America, after Brazil, Mexico, and Peru. The last country reported their first imported COVID-19 case on March $5^{\text {th }}, 2020$, and to the date of the data cut-off, they had more than 300000 confirmed cases and 12000 deaths registered. ${ }^{11}$

Considering that cumulative incidence of our country (183 cases per 100000 habitants) is underrated 8 times, at least, it is very probable that Mexico is among the most affected countries in Latin America, even without having reached a national maximum; on the other hand, Chile, Equator and Peru have already passed the climb of their national epidemic curves and show a descendent trend in the 
number of new cases, so making an exact comparison is not possible until Mexico has not reached the end of the epidemic Curve.

\section{Conclusion}

With the rapid assessment of the cumulative incidence of COVID-19 in the cities analyzed, a rapid, proactive, and comprehensive approach is essential to delay the spread of the SARS-CoV-2 virus in our country, with a change in the containment approach to one of mitigation, because the anticipated rapid increase in the number of cases may not provide decision makers and hospitals with sufficient time to understand the extent of this disease. The rapid risk assessment also lists public health measures to mitigate the impact of the pandemic. There is a brief window of opportunity in which countries can further increase their control efforts to slow the expansion of SARS-CoV-2 and reduce pressure on health care. However, the uneven adoption of control measures throughout the country, both in terms of time and obligation, and in terms of compliance on the part of the population, has led to outdated epidemic curves, which could complicate the overall control of the epidemic due to population mobility between different localities.

\section{Acknowledgments}

To open data portal of the government of Mexico for providing access to the database COVID-19 Mexico.

\section{Competing interests}

The authors declare that they have no conflict of interest.

\section{References}

1. European Centre for Disease Prevention and Control. Novel coronavirus disease 2019 (COVID-19) pandemic: increased transmission in the EU/ EEA and the UK-sixth update-12 March 2020. Stockholm: ECDC; 2020.

2. Alpuche-Aranda CM. Infecciones emergentes, el gran reto de la salud global: Covid-19. Salud Pública de México. 2020;62(2):123-124.

3. Jones KE, Nikkita G, Patel NG, et al. Global trends in emerging infectious diseases. Nature. 2008;451(7181):990-993.
4. Wang C, Horby PG, Hayden FG, et al. A novel coronavirus outbreak of global health concern. Lancet. 2020;395(10223):470-473.

5. Kinross P, Suetens C, Gomes Dias J, et al. Rapidly increasing cumulative incidence of coronavirus disease (COVID-19) in the European Union/ European Economic Area and the United Kingdom, 1 January to 15 March 2020. Euro Surveill. 2020;25(11):2000285.

6. World Health Organization (WHO). Statement on the second meeting of the International Health Regulations (2005) Emergency Committee regarding the outbreak of novel coronavirus (2019-nCoV); 2020.

7. Secretaría de Salud. Conferencia 29 de febrero de 2020. México SS; 2020.

8. Dirección General de Epidemiología, Secretaría de Salud de México. Coronavirus (COVID-19): algoritmos, avisos epidemiológicos y lineamiento. México: Secretaría de Salud; 2020.

9. Werneck GL, Carvalho MS. A pandemia de COVID-19 no Brasil: crônica de uma crise sanitária anunciada. Cad Saúde Pública. 2020;36(5):e00068820.

10. Geographic differences in COVID-19 cases, deaths, and incidence-United States, February 12-April 7, 2020. MMWR Morb Mortal Wkly Rep. 2020;69:465-471.

11. COVID-19 Americas' Regional Dashboard. Geographic Distribution of Cases and Deaths.

12. Patrick GT Walker, Charles Whittaker, Oliver Watson, et al. The Global Impact of COVID-19 and Strategies for Mitigation and Suppression. Science. 2020;369(6502):413-422.

13. Portal de datos abiertos del gobierno de México. COVID-19 Tablero México; 2020.

14. Instituto Nacional de Estadística Geografía e Informática (INEGI). Delimitación de las zonas metropolitanas de México 2015; 2018.

15. Comisión Nacional para la Vigilancia Epidemiológica (CONAVE). Oficio No. DGE-DG-DVEENT 02595/2020 Asunto: Vigilancia Epidemiológica COVID-19; 2020.

16. Covid-19: Data Summary NYC-Health.

17. Worldometers. COVID-19 Coronavirus Pandemic. 